\title{
Strategic human resource management in facilitating the organizational performance: Birds-eye view from Bangladesh
}

\author{
Md. Mahfuzur Rahman Khan
}

Research Scholar, Institute of Social Welfare \& Research, Dhaka, Bangladesh mahfuzur.rkm@gmail.com

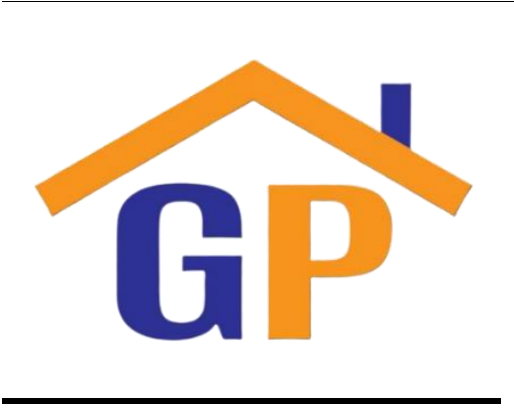

Article History

Received on 15 May 2021

Revised on 13 June 2021

Accepted on 22 June 2021

\begin{abstract}
Purpose: This study systematically explores and elaborates on strategic human resources management practices inside a company facilitating the intermediate variables of organization performance.

Research methodology: Ten organizations with more or less similar yearly turnover and the same number of permanent employees have been used for this study. The analysis technique in this study uses data analysis developed by Miles et al. (2018) as follows; (a) data collection (b) data display and (c) concluding. Focus group discussions with the employees and management of those companies are being taken with the help of a semi-structured questionnaire.
\end{abstract}

Results: The study's findings offered that the more strategic a company is with its human resource, the more turnover it can make, even if it has a similar number of human resources.

Limitations: There are shortcomings in theoretical research on the process of strategic human resource management practices affecting organization performance.

Contribution: This study offers a view to integrate and construct strategic human resource management activities affecting organization performance and provides a reasonable explanation and enlightenment for the understanding of further contribution.

Keywords: Strategic human resources management, Strategic goals of the organization, Organizational performance, Qualitative research, Bangladesh

How to Cite: Khan, M. M. R. (2020). Strategic human resource management in facilitating the organizational performance: birdseye view from Bangladesh. Annals of Management and Organization Research, 2(1), 13-24.

\section{Introduction}

Strategic human resource management (SHRM) is a planned human resource distribution and movement mode received to accomplish authoritative objectives and organizational goals. It joins the capacities and exercises of human resources management with the association's strategic objectives, underscoring HR. Organizations are progressively called upon to fortify their ability to adjust to changes, which constantly influence their current circumstance to guarantee their exhibition's maintainability and assurance. HR would subsequently assume a crucial part in the life and execution of any advanced association, as they comprise one of the vital variables in its capacity to react enough to the requests of this evolving climate. The literature supporting and showing the significance of HRM is discovered to be bountiful. The creator introduced in the accompanying area a few instances of creators who support this "connection" among HRM and organizational execution prior to introducing the literature identifying with the connection between HRM and organizational achievement. One of the primary purposes behind the significance of HR in organizational performance is this HR's capacity to foster the organization's versatility to changes that influence its current circumstance. 
Although there is no consensus on its view, HRM is considered to be a scientific field whose effectiveness has been proved by practitioners and research supported by economic theory and psychological theory. It seems that various studies and theories are mixed, but when they are integrated, the effectiveness of human resources toward the goal of "achieving the purpose of the organization" is centered on the paradigm of learning and performance. It can be said that it is an effort to bring about learning, performance, and change at the individual level, group level, and organizational level to enhance sexuality. In addition, from the classification of areas in existing research, it is found that they could be divided into two elements: individual development and organizational development. In companies, human resources management (HRM) has different missions and constraints depending on the organizational context. The particularity of HRM in specific contexts such as professional circles, HRM in the public context, HRM at the international level, and in emerging or developing countries, HRM in the context of organizational performance is now evident. In recent years, human resource management in the organization has shifted to strategic human resource management, and management has been strengthened from a strategic perspective. Therefore, the focus is on the relationship between organizational performance and strategic human resource management, while the emphasis on human beings as the human existence of human resources tends to be neglected.

In recent years, as the relationship between organizational performance and strategic human resources management has been demonstrated, attention has been focused on the "mediation process" between strategic human resources management and organizational performance, and there is a keen interest in research on the effects of employee attitudes and behaviors because of HRM's closer proximity. In this study, the clarification of current issues and the limitations of the research were discussed mainly through the literature review of his existing human resource management research. In developing countries like Bangladesh, national organizational performance and programs are undeniably vectors of economic growth. For these countries, which are still economically fragile and politically unstable, the control of the factors having an impact on organizational success and good governance is necessary for the governments in place. From this perspective, this study involving developing countries' (Bangladesh) perspective attempted to answer the following question: What are the factors that most influence the success of organizational performance in developing countries? Does HRM have an impact or a significant relationship with the success of this organizational performance? Organizations are turning out to be mindful that effective strategic human resource strategies and practices may build execution in various territories like efficiency, quality, and monetary execution. Indeed, even a small organization with as few as 10 staff possibly builds up a strategic plan to control choices about what has to come. In terms of strategic human resource management.

\section{Literature review}

The cutting-edge organization is progressively called upon to expand its adaptability and fortify its capacity to adjust to having the option to keep up its seriousness and guarantee its sustainability. From this perspective, skillful and adaptable HR would establish one of the key exhibition factors on which associations depend to improve their flexibility and keep up their intensity. The scholars and specialists of organizational management agree to argue that HR (human resources) would add to organizational performance improvement when managed appropriately and deliberately. The wave of change accompanies new ideas like occupational disease and organizational socialization. Regardless, paying little notice to the rising predominance of SHRM, there have been not a lot of precise evaluations of the cases that it is associated with execution and questions stay concerning its hypothetical establishments (Harris and Ogbonna, 2001). This examination planned to give a relative report on the job worker's play in organizational execution in light of SHRM practices in the setting of Bangladesh. Strategic human resource management (SHRM) addresses a modestly new change in the field of strategic human resources the executives.

SHRM is worried about the work strategic human resource management frameworks to play in firm execution, particularly focusing on the game plan of HR as strategies for gaining the high ground. The performance of exceptionally talented and propelled employees will be limited if jobs are not structured properly (Tsai, 2006). While some authors, like Thornhill and Saunders (1998), express that, the expanded job of line managers in managing human resources is the indispensable trait of any HRM 
model. According to Brewster and Larsen (2000), go further by contending that the devolution of HR duties to line managers is seen as a defining issue in HRM since line managers' actions and practices are generally answerable for the distinction among intended and actual HRM implementation. On the off chance that HR experts will hold a strategic job, the everyday HR exercises should be decentralized and shifted to line managers (Kulik \& Bainbridge, 2006).

On account of the fundamental course of action, organizations can build up a strategic HR plan that will permit you to settle on HR management choices presently to help the organization's future heading (Wan-Jing and Huang, 2005). Fundamental HR arranging predicts the HR's future needs in the wake of dissecting the organizations to analyze the associations' present HR, the external work market, and the future HR environment that the organizations will be working in (Tharenou et al., 2007). The literature on organizational performance management and organizational performance is almost unanimous on the importance of HRM practices in this organizational performance. In spite of what this literature proposes on the real job of HRM in the general execution of associations, it contends that HRM no affects the organizational success and is anything but a critical factor in this achievement. In addition, in spite of the fundamental pretended by organizational performance in the monetary and social advancement in developing Bangladesh, and notwithstanding the significance of the resources and endeavors contributed for their acknowledgment, the investigation of the literature shows us that the organizational performances completed in these Bangladesh experience high disappointment rates and disillusioning quality outcomes. To be sure, the literature instructs us that organizational management in these Bangladesh faces a large number of issues, which make the effective fulfillment of organizational performances a troublesome errand. This reality prompts us to scrutinize the purposes behind the disappointment of organizational performances in developing Bangladesh.

At the end of the day, in this study, we are keen on the connections between the key achievement factors and the result of this specific class of organizational performances, just as the spot that HRM would possess among these components. The response to these inquiries would help, as we would see it, to distinguish the wellsprings of accomplishment and additionally inability to decide the constituents of good management of these organizational performances and, subsequently, to advance their prosperity just as the accomplishment of their objectives. The literature on organizational success factors is both rich and different. Nonetheless, this literature stays conflicting concerning the elements that decide this achievement. For sure, an investigation of the literature has shown us that the authors are not yet consistent on the achievement components of organizational execution and the actual meaning of progress. What is more, the literature on organizational performance in developing Bangladesh stays extremely restricted and, just once in a while, addresses the achievement variables of this specific classification of organizational performance.

\section{Theoretical framework}

Human Resource Management (HRM) has been formed into strategic human resource management (SHRM) by industry experts looking to stress the meaning of the plan to the practical working of organizations. To this end, various makers have kept up that SHRM is clearly associated with progressive execution and there is moreover a social event of industry specialists who are of the appraisal that high-performing work associations give phenomenal thought to getting explicit HRM courses of action and interfacing these to the systems of their organizations. Companies are constantly exposed to changes in the environment. In the field of "human resources," the field of human resources has undergone major changes in the last 10 years, and it can be said that the role of the human resources development department linked to management is increasing more than ever. There is no time to list the big and small issues such as the shortage of human resources due to the declining birthrate and aging population, the influx of foreign workers due to it, and the measures for diversity due to the globalization of business.

Surprisingly many companies have not been able to resolve the organizational and conscious issues surrounding their human resource development before work style reform. It seems that these companies are unaware of the potential issues in their organizations, or even if they have become apparent, they do not know how to solve them. That is why the demand for quality human resources is global. The 
demand for the export of human resources in international trade is increasing as the demand for qualified persons is increasing. In such a situation, many Bangladesh is exporting human resources by educating the people of their country in higher knowledge, science, and technical education. According to Guthrie (2001), strategic human resource management literature includes formal performance appraisal, skillbased pay, and group-based pay, which have all been linked to organizational performance (Guthrie, $\underline{2001)}$.

\section{Objective of the study}

This study focuses on human resource management in facilitating the organizational performance (identified in the literature) carried out in developing Bangladesh, the country taken, as a model in Bangladesh. In particular, the author is interested in the relationship between strategic human resource management and organizational performance. From this perspective, the research objectives are as follows:

- To identify the relationships between human resource management and the success of organizational performance in developing country like Bangladesh

- To examine the role of SHRM and how it affects organizational performance in firms of Bangladesh

- To examine the organizational strategies used in SHRM to enhance performance at Bangladeshi organizations

\section{Methodology of the study}

The study has been conducted using qualitative means, as qualitative research intends to examine and discover issues about the issue accessible because close to no is contemplated the issue. There is, for the most part, weakness about estimations and characteristics of the issue. In the light of all these elements, our study sets itself the objective of contributing to the enrichment of knowledge on the importance of strategic human resource management in organizational performance by deepening the controversy relating to the role of SHRM in the success of organizational performances. To do this, the author plans to orient our research towards the specific context of organizational management in developing countries like Bangladesh. Ten selective organizations have been taken as the sample model organization. The organizations taken have the same number of permanent employees and quite similar yearly turnover. Focus group discussions (FGD) have been taken through a semi-structured questionnaire to understand the author's context better.

Table1. Description of organizations used as model

\begin{tabular}{|c|c|c|c|c|c|}
\hline Code & $\begin{array}{c}\text { Industry } \\
\text { Operating }\end{array}$ & Location & $\begin{array}{c}\text { Permanent } \\
\text { Employees }\end{array}$ & $\begin{array}{c}\text { Years of } \\
\text { Operation } \\
\text { (Approx.) }\end{array}$ & $\begin{array}{c}\text { Yearly } \\
\text { Turnover (in } \\
\$ \text { ) }\end{array}$ \\
\hline SO_1 & Delivery & Dhaka & 13 & 5 years & 0.14 millions \\
\hline SO_2 & Delivery & Dhaka & 13 & 5 years & 0.16 millions \\
\hline SO_3 & Delivery & Dhaka & 13 & 5 years & 0.143 millions \\
\hline SO_4 & Agriculture & Savar & 13 & 5 years & 0.19 millions \\
\hline SO_5 & RMG & Savar & 13 & 5 years & 0.119 millions \\
\hline SO_6 & RMG & Narayanganj & 13 & 5 years & 0.189 millions \\
\hline SO_7 & RMG & Narayanganj & 13 & 5 years & 0.14 millions \\
\hline SO_8 & Book Publication & Dhaka & 13 & 5 years & 0.12 millions \\
\hline
\end{tabular}




\begin{tabular}{|c|c|c|c|c|c|}
\hline Code & $\begin{array}{c}\text { Industry } \\
\text { Operating }\end{array}$ & Location & $\begin{array}{c}\text { Permanent } \\
\text { Employees }\end{array}$ & $\begin{array}{c}\text { Years of } \\
\text { Operation } \\
\text { (Approx.) }\end{array}$ & $\begin{array}{c}\text { Yearly } \\
\text { Turnover (in } \\
\$ \text { ) }\end{array}$ \\
\hline SO_9 & Book Publication & Chittagong & 13 & 5 years & 0.155 millions \\
\hline SO_10 & Book Publication & Chittagong & 13 & 5 years & 0.16 millions \\
\hline
\end{tabular}

\section{SHRM in facilitating the organizational performance}

Organizations ought to have the alternative to complete a lot of orchestrated and altogether analyzed strategic human resource management thoughts that must be executed to facilitate just as to channel the human resources into expanded profitability. As demonstrated by Torrington et al. (2011), a solid strategic human resource technique permitted a business to have a decent comprehension of its workers and to work tranquility, similarly in a normally productive path with its host local area. Research between strategic human resource management and productivity has influenced the scholastic and laborers banter for over thirty years. In any case, most examinations and distributions in the field of strategic human resource management have given the idea as far as individual practices. As indicated by Noe et al. (2007), it alludes to strategic human resource management practices and approaches affecting work, perspectives, and execution of employees. As expressed by Marvel (2011) they are centered on numerous fundamental practices and thus, can decidedly affect organizational performance, for example, human resource planning, recruitment, selection, training and development, compensation, performance management, and worker relations. Fundamentally, in human resources development, emphasis has been laid on acquiring knowledge, proper use of resources, healthy, and quality of life. The manager needs to properly supervise the assigned work by analyzing each employee's personality, preferences, work ethic, loyalty, family tradition, educational qualifications, etc. Every human resource should be developed as an economic entity. Motivation is the fuel, the driving force of the workforce, which is the best tool to increase productivity. Discipline, love for the organization, creativity, inspiration, good supervision, etc. can be used to make the workforce creative. As, Mr. Hakim, who currently run a business of book publication, conveyed,

"For over 10 years, I drove an association that puts on books for distributions for the most part in February. It was anything but a major creation, with just 13 individuals taking an interest in excess of 20 exhibitions. Before the finish of the period, each and every individual who took an interest was depleted. In any case, with my strategic reasoning, I made it increasingly inventive and fruitful." (SO_10)

At present, with the rapid development of globalization and technology, any organization is facing various challenges. To address this challenge, it is necessary to create a good working environment in the organization and create enthusiasm among the workforce. Every employee should be provided with professional and advanced training on the computer. Employees must be given due recognition of their work because the primitive desire of the man is to get the recognition of others. The first strategy to motivate employees is to treat them friendly, giving them due respect. To ensure self-improvement and job satisfaction of the workforce, the manager has to undertake various work plans. Job satisfaction is found only if the desired return of the employee is consistent with the expectation. Workplace nature, work environment, salary-allowance, good relationship with colleagues, clear supervision system, institutional environment, etc. are the tools of job satisfaction. The main goal of human resource development is human welfare. At present human resources are not just a unique tool of production; Rather the actual capital of the organization. Proper development of the organization's human resources is possible if a skilled manager takes all the steps properly.

Human resource development is a process of qualitative transformation of human resources through which they can become productive and skilled human resources. These human resources can play a strong role in the production process and can develop to the best of their ability. Every organization runs after the acknowledgment of a mission and a dream, which are accomplished by detailing certain systems and executing them, which are completed by the HR division. It begins by communicating why 
organizations need to receive a strategic attitude, which infers an adjustment of the disposition of senior management. The principal stages and exercises of the strategic management model are raised, different meanings of the procedure given by different creators are offered, the segments and levels of business methodology, clarifying every one of these levels to clarify that at the third level, that of the practical system is the place where the exercises of the strategic management of HR ought to be completed. Mr. Niloy, who have been doing agriculture-based company for over 5 years in Savar, Bangladesh conveyed,

"It took me some time to discover that specific individuals may have significant abilities that are not in every case blazingly clear. Step by step, I came to acknowledge - moderate as I may have been - that what made a difference was execution. Occasionally, individuals may be assisted with creating, and that it takes assorted types to make an organization run appropriately. Great execution responsibility is tied in with having a positive discussion among managers and employees." (SO_4)

Strong political, monetary, and social changes permit social orders to go through a significant advancement in their strategic mindsets, combined with this the serious level of a mechanical turn of events and the capacity to absorb progressively current methods that permit managers to give a strategic vision to anticipate the eventual fate of business the board and pad however much as could be expected the degree of vulnerability that describes business action during circumstances such as the present. These necessities give strategic human resource management need for directors at all levels. The strategic management of HR is at present the object of exceptional consideration from directors, not just in view of the job it plays in the turn of events and utilization of the organization's methodology yet in addition due to its immediate and prompt impact on the generous and supported development of usefulness.

The progressions that have occurred, both in the origination and in the capacity that have been credited to the human factor lately, make entirely good conditions so that, as of now, the human resources department can be considered as a strategic capacity with a functioning job, both in the detailing of the procedure and in its execution. Key HR should give efficient, proactive, and adaptable transformation to changes in the climate, and have a dream of things to come reconciliation into the generally strategic methodology of the organization, which is accomplished if, while figuring any system, they consider the ramifications that this technique has on HR; the HR procedure that exists today and on the off chance that it fulfills the new strategic methodologies. The HR methodologies that should be fostered that give successful reactions to their new necessities, as far as the critical parts of HR, are fundamental for every system and give the organization the upper hands.

\section{Results and findings}

Strategic human resource development is a process of qualitative transformation of human resources. Its productive and efficient human resources can make an increasingly robust contribution to the production process and develop the best of human potential. So human resource development is the key to all development. Numerous components are remembered for the human resources management zone, including manager marking, enrollment, onboarding, maintenance, advancement, culture, the profession of the executives, portability, progression arranging, ability of the board, execution of the board, employee organization, and legitimate issues (Khan, 2020a).

Strategic human resource management has been generally worried about the effect of HR procedures on organizational performance (Boxall \& Macky, 2007). If there are skilled human resources, foreign investors are easily attracted. Therefore, in the interest of the country, the population must be turned into human resources. Human resources are considered the engine of development. Currently, this resource is considered the most important resource of a country. Their skilled human resources are the main driving force for the development of a limited country. Therefore, in the interest of development, human resources must be developed. Human resource development is the center of all kinds of development. In addition, education is the main way to develop human resources. Primary, secondary and higher education enhances people's skills manifold. Increasing the rate of education and well- 
chosen higher education is conducive to rapid economic growth. Education has played an important role in the development of human resources in several Bangladesh.

When human beings are considered a tool of development, the issue of human resources comes to the fore in the implementation of development programs. Nevertheless, even though a large number of people are unemployed, suitable people cannot be found. This requires appropriate secondary and higher education and adequate technical and vocational education opportunities to create a qualified strategic human resource with appropriate skills. However, there have been significant changes in the concept of development. Only a few centuries ago, resources were considered a key determinant of development. The richer a country is, the richer it is, the more developed it is. Now, 'people' are considered as the focus of development. Mr. Rakib, a book publisher, defines,

"Having a privilege and consistent execution of the strategic human resource management framework assists an organization with changing over, screen, give criticism and course right; plan the drawn-out destinations and its execution. Organizational viability does not lie in that intolerant idea called discernment. It lies in the mix of sensible rationale and incredible instinct. SHRM continues to be an important cornerstone of the business and individual growth and development" (SO_9)

Therefore, it remains to be seen whether the resources are being used for the welfare of the people. It is now being said that a country can be called developed only when the human development situation in that country is at a satisfactory level. There is a marked tendency to look at employees, who are human resources, as physical resources. Although they regard employees as "social resources," they treat organizational strategy primarily. For that purpose, they use various employment forms in combination within the company, and they are diverse. It insists on introducing various employment forms in parallel. However, in a situation where the organizational environment continues to change, it is clear that flexibly applying various employment forms has an advantage on the organizational side to improve the efficiency and smoothness of employment adjustment.

There is a lack of consideration for employees' desires, and there is a tendency to neglect humanity. In other words, in a situation where various employment forms are adopted within the same company and employment adjustment can be carried out efficiently, employees have no choice but to comply with the company's request while suppressing individual desires. On the other hand, in such a situation, it is assumed that the company has a false perception that a cooperative labor-management relationship has been established with a superficial state that employees do not complain dissatisfaction or request. If so, the results inevitably are entirely different from the original direction they seek for human resource management.

\section{Discussion}

Strategic human resources are one of the strategic elements for the overall development of a country. The role of skilled human resources is vital for economic growth, sustainable and long-term development. Therefore, despite the abundance of financial resources and physical resources, the development process slows if there is a lack of human resources. Human resource development is strategic for the socio-economic development of Bangladesh. Human resource is an economic suffix. Economists have interpreted it from their point of view. Modern economists think that human beings are like other resources. However, human energy only becomes human resources when it is managed in a well-planned way. In an organizational structure, all the factors had a significant correlation with the success of the organization except for the "Planning," "HRM," and "Communication" factors. Finally, in a matrix structure, the only factor that does not have a significant correlation with success is "HRM." It seems surprising that HRM is not significantly associated with success in any type of organizational structure. Indeed, the literature teaches us that HRM is one of the key factors for organizational success, at least in a functional type structure. Now, let us look at some of the functions in strategic form.

\subsection{SHRM planning}

In an organizational context, several obstacles hamper HR planning. First, the uncertainty as to whether the organization even be obtained at the end of the call for tenders and the completion of the organization 
through all its stages makes it difficult to predict future HR needs and their use definitively. Second, the organizational manager is often hired after organizational approval, which limits him in his HR planning strategies. The goals of strategic human resource requirements planning are to determine how many employees are required at what time and with what qualifications at a particular location to be able to fulfill the required workload. To determine the strategic human resource requirements, the tasks to be fulfilled as well as their quantitative and qualitative requirements, must first be determined. In the quantitative determination of strategic human resource requirements, the number of employees required to cover short-term or long-term capacity requirements is ascertained. The qualitative determination of strategic human resource requirements, on the other hand, specifies the level of qualification of the employees to cover the competence requirements. A detailed description of the work task is in the foreground in qualitative strategic human resource recruitment. In doing so, the tasks of the position manager as well as any organizational relationships must be taken into account. The scope and type of work are determined to be able to record the requirements for employees in the job description.

\subsection{Strategic human resource recruitment}

The main task of strategic human resource recruitment is to resolve to understaff. The newly acquired staff should correspond to the company's expectations both in terms of quality and quantity and space and time. For this reason, the existing workforce is adjusted to the required staffing requirements through internal recruiting and new appointments. In principle, the area of recruiting can be divided into external and internal processes. The recruitment but also information of potential workers on the free labor market are components of external strategic human resource recruitment. 9 The main task can be defined as the acquisition of performance potential as a resource in one's own company. The prerequisite for this is that comparable potentials cannot be developed with the existing workforce. External strategic human resource recruitment methods have become more comprehensive due to technical progress, in contrast to the past.

One of the most classic instruments, which is still used, is the job advertisement in print and digital media. When a position becomes vacant or when a new position is created, it is also possible to identify internally qualified applicants. The main goals include saving any training costs and promoting and using existing know-how in the company. The traditional approach to recruitment (job description, identification of candidates, posting, etc.) is generally not appropriate for the organizational context. The use of independent professionals and subcontractors is a means widely used in this context. In addition, the selection of the manager and the organizational team is of particular importance for the realization of the organization. The organizational manager occupies a critical and privileged position. To assume his responsibilities successfully, he must have developed skills in management (planning, organization, supervision, and control), decision-making, communication, and leadership, in addition to solid technical expertise. . Selecting an effective organizational manager is, therefore, a big challenge for the HR function. On the other hand, the selection of the organizational team is often carried out by the functional manager and rarely involves the organizational manager, while the latter's participation in this selection is recommended.

\subsection{Strategic human resource development}

The development and promotion of high performers in the company are becoming increasingly important. The fast-paced change in the labor market leads to a lack of knowledge and thus requires employers to continuously develop the qualifications of their employees. A wide variety of organizational and technical developments also require a constant learning process. The loyalty of high performers to the company is strengthened by qualitative strategic human resource development. Ordinary people can become human resources only if they acquire knowledge and skills in various fields. The improvement, reputation, and excellence of an organization depend on the proper empowerment of human resources. The manager's main responsibility is to achieve the desired goal of the organization by improving the ethical quality of human resources, expertise in technology, and service-oriented attitude. The success or failure of the organization largely depends on the implementation of the manager's practical decisions. The wisdom, honesty, and foresight of the manager are what drives the organization forward. Human resource development means proper selection, 
deployment, training, motivation, and maintenance of the workforce so that a promising commitment is made to the organization's overall development.

\subsection{Strategic human resource retention}

The defined goal of every company should be to bind qualified and motivated employees to the company in the long term and to establish an emotional connection between the employees. Employee retention is of crucial importance for any type of corporate strategy. An excessive fluctuation of employees can be counteracted by implementing appropriate methods for staff retention. The term fluctuation describes the change of an employee to another company or the retirement for reasons of age or the employee's death. If one of these reasons occurs, there is usually a need for replacement in the company. The costs involved can be very high. For an employee, the directly chargeable costs are around half an annual salary.

The area of responsibility extends from the acceptance of new employees to the regulation of salary and service issues to the termination of active employment relationships. Further agendas of the strategic human resource office are the processing of subscription-related matters - particularly the assessment of salaries and the granting of holidays, parental leave, and part-time employment. Through the main methods of human resource development, the levels of skills and capabilities can be known, which provide high returns and are helpful for economic development. In this way, the potential for better utilization of each limited resource increases. If there is little appropriation on human resources, labor skills will be low, there will be a lack of entrepreneurship and social institutions will be able to work at a low level. In less developed Bangladesh, it is seen that the absorption capacity of physical capital is poor, as there is a lack of technically skilled persons, training labor, and administrative skills. Human resource planning is considered necessary to overcome these weaknesses.

Human resource planning informs the process that takes into account the objectives, policies, and programs for the use and distribution of human resources for achieving economic and other goals. Human resource planning involves the development and efficient use of managerial, scientific engineering, and other technical skills to create, expand, and develop organizations. There should be an increase in the functioning of productive services, organizations, and economic institutions. In this, the specificity of human skill required for each major action is given and the nature and timing of these requirements are taken into consideration. It makes extensive use of existing institutions and establishes new institutions so that the desired amount of human resources is available at the right time. It takes note of the synergy of various training institutes.

\subsection{Strategic job analysis}

While emphasizing the complexity of the job analysis of the organizational management, the authors propose a job description of the organizational management, which boils down to coordinating the various material, financial and financial resources. The organizational manager is called upon to play the roles of integrator, communicator, leader, decision-maker, and coordinator at the same time. These responsibilities are demanding and critical for the success of the organization. However, often the organizational manager has only limited authority. Job analysis highlights the significant job of HR during the time spent the monetary turn of events. It tests the present and future human resource requirements and prospects through available human resources. Policy formulation is made for the appropriation of human resources through human resource analysis by which the limited resources of developing nations can be used efficiently. This makes it possible to specify the obstacles that come in the way of better utilization of human resources.

\subsection{Strategic human resource appraisal and compensation}

With repeated changes in assignments and responsibilities among organizational staff, it is difficult to establish a strict salary classification. One of the most common compensation practices in an organizational context is merit-based compensation based on performance appraisal. Such a system aims to maintain staff motivation by providing some stimulation to maximize performance. Performance appraisal is complex in an organizational context as it becomes almost impossible to rely on the sole annual interview with the line manager. Several actors can intervene in the evaluation of strategic human resource performance, jointly or separately. Indeed, in a matrix structure, the evaluation 
can be done in different ways: the evaluation of the team members by the organizational manager who transmits the evaluations to the functional superiors; the evaluation of team members by the organizational manager without transmitting the evaluations to functional superiors, the evaluation carried out entirely by the functional superior; joint assessment by the organizational manager and the functional manager.

\subsection{Strategic human resource training}

The author emphasizes the importance of training in an organizational context and its multiple advantages (improved performance, reduced costs, increased motivation, etc.). The training system in the organizational context should promote the development of four skills related to technique, human resources, knowledge of the company, and the ability to adapt. To keep pace with the upcoming challenges, graduates of Bangladesh have to be skilled in digital devices and other modern technologies for the competitive job market (Khan, 2020b). The most used training means and the most adapted to this context are, among others, training in the form of information meetings, on-the-job (on-the-job) training of new employees by former employees. Though training outside the framework for specialized programs, the job rotation system allows the widening of the employees' knowledge base, learning by simulation, and training in the form of workshops.

\subsection{Satisfaction of strategic human resource}

The immediate effect of employee satisfaction is the employee's organizational responsibility and steadfastness. Fulfilled employees can expand their feeling of character with the association, subsequently showing an ability and steadfastness to turn into an individual from the association and to add to the association for quite a while for the effect of employee satisfaction, we can study from two aspects, one is the impact analysis of the relationship between employee satisfaction and the organizational commitment of employees, and the other is the impact analysis between employee satisfaction and employee loyalty. The analysis of these two points belongs to the category of human resource output.

The loyalty of employees to the organization has an impact on the behavior of employees. Loyal employees exhibit organizational citizenship behavior $(\mathrm{OCB})$ and commit to practices reliable with the organization's advantages, like higher work proficiency, lower costs, proactively proposing more sensible cycles, and great assistance mentalities, Service productivity, and so on, to manage client relations all the more sensibly and tenaciously. Accordingly, this disposition and conduct of workers straightforwardly affect the proficiency of the organization's inner activities and consumer loyalty. We desire to get the consequences of "the authoritative responsibility of employees is emphatically identified with the effectiveness of interior activities," "the organizational responsibility of workers is decidedly identified with consumer loyalty," and obtain specific impact coefficients.

\subsection{Career planning of strategic human resource}

In organizational management, career planning is a popular way of giving promotions to employees. It constitutes a privileged means of retention. The organizational manager, for example, is initially assigned to short-term organizational performance to provide him with training in organizational management. Subsequently, he/she must be involved in larger organizational performance. He/she will thus have gradual promotions according to the skills developed. Not all organizational workers are sure about the possibility of a specific career. However, they have the opportunity to have varied careers and play different roles in a "spiral career". HRM should figure among the factors associated with organizational success in a functional structure, especially since in this type of structure, the HR function is omnipresent and it is easy to identify its role and its activities. Under the wise guidance of the manager, the workforce turned into a self-motivated and committed human resource. In the organization's interest, the manager has to make the necessary reforms or changes to make the mindset of the employees aware. There is no substitute for reform and change to retain the organization's brand and make it famous. A skilled manager thinks beyond the norm and keeps the alternatives to himself. 


\section{Conclusion}

Strategic human resource practices can straightforwardly influence employee inspiration, worker abilities, and worker interest, subsequently straightforwardly influencing employee fulfillment. Organizations can utilize powerful motivation components to urge employees to work for the objectives of the organization; through successful enlistment, preparing, advancement, and different intends to improve the abilities of workers, and improve their capacity and level of management to the organization; through the organization's correspondence system and support, it permits workers to have the chance to partake in the business the executives' exercises of the endeavor, in this way having the chance to all the more likely assume their part. The creator can comprehend the effect of the organization's human resource rehearses on employees through the examination of worker fulfillment. What we are searching for here is the connection between the organization's human resource practices and employee fulfillment. The author expects to get a result that "positive human resource policies and practices must lead to employee satisfaction" and find specific impact relevance. Mr. Alam, who has been leading an RMG company for over five years in Savar, Bangladesh, stated,

"Nobody of the information needs an organizational strategy. The authoritative arrangement can just obstruct the progression of information. There is a fundamental inconsistency between any organization and opportunity of thought. When dealt with handily in an organization today, organizational performance can build work fulfillment, employee maintenance, devotion, and strategic execution of the organization." (SO_5)

There is also the development of organizations and institutions that conduct strategic human resource programs. Human resource planning is different from economic planning. In economic planning, optimum development is taken into consideration in the use of material and economic resources, while in human resource planning, the development of the ability, skill, knowledge, and motivation of individuals is taken into consideration. The author thus proposes two reasons for these "surprising" results. First, this study focuses on what people and teams do, rather than on the quality of their human interactions or motivational or decision-making practices. Second, there are strategic human dimensions in almost every HR function that were discussed in the discussion part. According to the author, it should not be understood that there are factors involving only processes and other factors involving only human resources. It is only by taking into account the duration of the organization as a moderating variable that it has been shown that these HRM practices positively influence the success of the organization. The duration of the organization thus exerts, according to these authors, a moderating effect on the relation between the development of HR and the success of the organization. Thus, the HR development practices of the organization, in particular of the organizational team, would only have a positive impact on the success of the organizational performance in the case of organizational performance carried out over a long period.

The debate thus turns out to be far from over about the existence or not of a relationship between HRM and the success of organizational performance. Indeed, several empirical studies contradict the general tendency that SHRM is a decisive factor in organizational performance. Suppose the literature is almost unanimous on the impact of HRM on the overall performance of organizations. In that case, the impact of strategic human resource management practices on organizational performance is a complex and multi-linked systematic process. To better explain the process and mechanism of the impact of human resource management practices on organizational performance, and break the black box state of the relationship between strategic human resource management practices and organizational performance, this paper introduces the analytical framework of the balanced scorecard to integrate organizational behavior and strategy Management and other related theories have obtained a process and mechanism model of the impact of human resource management practices on organizational performance. This has explanatory solid and enlightening significance for understanding the contribution process of human resource management practices to organizational performance. At the same time, this article also proposes a better research framework for empirical research. To define and measure the level of influence of various intermediate variables, future research can put forward hypotheses based on the model and conduct an empirical analysis to demonstrate its value in practical applications. 


\section{Limitations and study forward}

There are still many shortcomings in theoretical research on the process of strategic human resource management practices affecting organization performance. Recently, the study of the impact of strategic human resources management (SHRM) in the context of organizational performance has become a crucial subject whose measurement is necessary to ensure the sustainability of organizational performance. The controversial findings on the existence of significant relationships between strategic human resource management and organizational success now call for further research on the subject.

\section{Acknowledgment}

The author acknowledges there was no external funding support; the author solely contributed accordingly in every part of the paper.

\section{References}

Boxall, P., \& Macky, K. (2007). High-performance work systems and organisational performance: Bridging theory and practice. Asia Pacific Journal of Human Resources, 45(3), 261-270.

Brewster, C., \& Larsen, H. H. (2000). Human resource management in Northern Europe: trends, dilemmas and strategy. Blackwell Publishing.

Guthrie, J. P. (2001). High-involvement work practices, turnover, and productivity: Evidence from New Zealand. Academy of management Journal, 44(1), 180-190.

Harris, L. C., \& Ogbonna, E. (2001). Strategic human resource management, market orientation, and organizational performance. Journal of business research, 51(2), 157-166.

Khan, M. M. R. (2020a). Rationalizing the Relationship between Ergonomics and Human Resource Management. Journal of Mechanical, Civil and Industrial Engineering, 1(1), 31-35.

Khan, M. M. R. (2020b). Covid-19's impact on Fresh Graduate's Job Market in Bangladesh: An observational study. Journal of Business and Management Studies, 2(1), 40-48.

Kulik, C. T., \& Bainbridge, H. T. (2006). HR and the line: The distribution of HR activities in Australian organisations. Asia Pacific Journal of Human Resources, 44(2), 240-256.

Marvel, M. R. (2013). Human capital and search-based discovery: A study of high-tech entrepreneurship. Entrepreneurship theory and practice, 37(2), 403-419.

Miles, M. B., Huberman, A. M., \& Saldaña, J. (2018). Qualitative data analysis: A methods sourcebook. Sage publications.

Noe, R. A., Hollenbeck, J. R., Gerhart, B. A., \& Wright, P. M. (2007). Fundamentals of human resource management.

Tharenou, P., Saks, A. M., \& Moore, C. (2007). A review and critique of research on training and organizational-level outcomes. Human resource management review, 17(3), 251-273.

Thornhill, A., \& Saunders, M. N. (1998). What if line managers don't realize they're responsible for HR?. Personnel Review.

Torrington, D., Hall, L., Taylor, S., \& Atkinson, C. (2011). Strategic human resource management. Human resource management, 57, 76.

Tsai, C. J. (2006). High performance work systems and organizational performance: an empirical study of Taiwan's semiconductor design firms. The International Journal of Human Resource Management, 17(9), 1512-1530.

Wan-Jing, A. C., \& Huang, T. C. (2005). Relationship between strategic human resource management and firm performance: A contingency perspective. International Journal of Manpower, 26(5), 434. 